\title{
La inscripción del Patrimonio de las Corporaciones municipales y el concepto de tercero hipotecario
}

Una de las facultades de los Ayuntamientos, elevada a la categoría de obligación por el artículo 153 de la vigente Ley Municipal de 31 de octubre de 1935, es la relativa a la inscripción en el Registro de la Propiedad de sus bienes inmuebles y derechos reales.

Mas en la práctica, en ocasiones sucede que, por falta de titulación, no puede llevarse a efecto este transcendental acto jurídico, de importancia singular para la vida administrativa de los Municipios.

Pero el propio precepto antes invocado viene en gran parte a resolver el problema, al disponer que, para seguridad de su Patrimonio, las Entidades municipales tendrán facultad y (obligación) de inscribir en el Registro de la Propiedad sus bienes inmuebles y derechos reales mediante certificación que, con relación al inventario aprobado por la Corporación respectiva, expida el Secretario con el visto bueno del Alcalde, la cual será inscribible y producirá iguales efectos que una escritura pública.

Queda dicho que este artículo ha venido a resolver en parte sólo la dificultad indicada, ya que para obtener la inscripción de los bienes patrimoniales municipales por el procedimiento apuntado, es preciso atenerse a lo dispuesto en los artículos 24 al 30 del Reglamento Hipotecario de 6 de agosto de 1915, que arranca y procede del Real Decreto de 11 de noviembre de 1864, a tenor de cuyo artículo 26, sólo se puede inscribir la posesión, no el dominio pleno o nuda propiedad.

Perfecto paralelismo guarda el artículo 153 de la Ley con el 22 del Reglamento de Hacienda Municipal de 22 de agosto del año 1924, al 
disponer que todos los bienes, derechos y acciones que constituyan el Patrimonio municipal, deberán estar catalogados y valorados, y siempre que sea posible deberán existir planos de plantas y alzados de los edificios y los parcelarios, que determinen gráficamente la cabida y linderos de los inmuebles rústicos con referencia a vértice de triángulo de tercer orden o topográfico, o a puntos culminantes o fijos de los terrenos. A tal efecto, las 'Comisiones permanentes y las Juntas vecinales formarán, dentro del primer año de su constitución, inventario general de los respectivos patrimonios. Este plazo será de tres años para los Ayuntamientos de más de 100.000 habitantes.

En el inventario, que comenzará con los bienes inmuebles, y con referencia a las hojas extracto de las titulaciones, se determinará el nombre, situación y demás circunstancias de las fincas:-carácter, linderos, clase, extensión y forma geométrica en planta; el título de propiedad o posesión que ostente el Ayuntamiento y origen del mismo ; gravámenes, etc., etc., y termina diciendo que los inventarios se rectificarán anualmente, y que tanto su aprobación como las rectificaciones corresponderán al Pleno, con vista de las certificaciones que deberán expedir el Secretario o el Interventor, según los casos. El inventario será revisado siempre que se constituya nuevo Ayuntamiento, consignándose al pie del mismo el resultado de la revisión, a fin de establecer las responsabilidades que correspondan a la nueva Corporación municipal o a la saliente.

A llenar la laguna jurídica apuntada, de la imposibilidad, en algunos casos, de inscribir el "dominio» de los bienes inmuebles pertenecientes a las Corporaciones municipales, ha venido el artículo 206 de la vigente Ley Hipotecaria de 8 de febrero del año en curso de 1946, al disponer que, (el Municipio, cuando carezca de título inscrito de dominio, podrá inscribir el de los bienes inmuebles que le pertenezcan mediante la oportuna certificación librada por el "funcionario" a cuyo cargo esté la administración de los mismos, en la que se expresará el título de adquisición o el modo en que fueron adquiridos».

Examinemos detenidamente, para evitar confusiones, que el artículo que comentamos (L. H.) dice que la certificación la librará "el funcionario» a cuyo cargo esté la administración de los mismos.

¿Cuál es este funcionario? ¿El Alcalde? No. Aunque de su interpretación gramatical así pudiera deducirse. El funcionario que deberá expedir la certificación a que nos referimos es el Secretario. 
Robustece este aserto el artículo 26 del Reglamento Hipotecario, al disponer que el jefe de la dependencia a cuyo cargo esté la administración o custodia de las fincas que hayan de inscribirse, expedirá por duplicado, "siempre que por su cargo ejerza autoridad pública» o "tenga facultad de certificar») una certificación en que "refiriéndose al inventario o a los documentos oficiales que obren en su podern. Por consiguiente, la facultad de expedir la certificación es privativa del Secretario, ya que certificar y dar fe son términos sinónimos, y puesto que fedatario es la persona que da fe de algo, que certifica algún hecho o que acredita la realidad o el contenido de un documento, el Secretario es, con excepciones contadas, el único fedatario municipal, porque si bien es cierto que el Alcalde certifica diversos extremos, no obstante, cuando se trata de certificaciones que hagan referencia a los libros y documentos relacionados con la administración municipal, es el Secretario y no el Alcalde quien certifica.

Vemos, pues, que el campo de actuación del Secretario se amplía en horizontes dilatados al compás que se legisla, y se ensancha su órbita de actividades netamente jurídicas, pues la señalada en el artículo 206 de la Ley Hipotecaria vigente, bien puede calificarse de notarial, sin incurrir en petulancia exagerada, tan sólo comparable a la contenida en el artículo 1.324 del Código Civil.

El artículo siguiente de la Ley Hipotecaria, es decir, el 207, dispone textualmente que, "las inscripciones de inmatriculación practicadas con arreglo a lo dispuesto en el artículo anterior no surtirán efectos respecto de tercero hasta transcurridos dos años desde su fecha».

Pero, ¿qué es y quién es tercero a estos efectos? Para concretar este concepto resulta obligado acudir a la doctrina, pues como dice Castro, el concepto de tercero no es algo exclusivo de la Ley Hipotecaria. Esta no ha elaborado los conceptos de nulidad, rescisión, propiedad, derechos reales y otros muchos que pertenecen extrictamente al Derecho Civil. El Derecho Hipotecario recibe estos elementos ya formados y elaborados, no haciendo más que someterlos a las consecuencias derivadas de los principios del sistema que establece. Pues bien, lo mismo hay que decir de los conceptos de tercero y de parte.

En el orden civil, tercero es el que no ha sido parte en un negocio jurídico que puede afectarle. Su posición se ve clara en materia de contratos. Tercero es el que no ha sido parte en el contrato especialmente corttemplado. Partes son, en cambio, las personas que 
los otorgan, los sujetos que lo celebran. Como dice don Jerónimo González, el concepto de tercero es aplicable a aquel que no es elemento personal de un determinado negocio jurídico, y antes bien, se contrapone a las dos partes que corrientemente lo engendran.

Para completar la idea de tercero, hay que precisar los efectos de los contratos.

Los efectos más especificos son los vinculantes u obligacionales. Se producen solamente entre las partes contratantes y sus herederos (artículo 1.257 del Código Civil). Los terceros quedan fuera de estos efectos por el principio «res inter alios acta alüs nec nocet nec prodest).

Efectos de afección.-Si bien los contratos no obligan, afectan a tercero. El Código Civil, artículo 1.218, dice que «los documentos públicos hacen prueba aun contra terceros), y en cuanto a documentos privados, el artículo 1.227 viene a suspender, como precaución contra confabulaciones posibles, el valor y eficacia de los mismos respecto de tercero, hasta que resulta ser cierta su fecha por uno de los medios que señala.

Por tanto, los contratos afectan a terceros en el sentido de no poder éstos considerarlos como inexistentes, pues sólo se elimina esta afección cuando no concurre una garantía de autenticidad.

Con lo dicho queda precisado el concepto de tercero y su posición jurídica en general. Mas dentro de esta noción, hay que distinguir dos tipos de terceros: el tercero simple y el tercero adquirente.

El tercero simple, es aquel que es completamente extraño o ajeno a un contrato en cuestión, debido al hecho de no haber tenido relación jurídica alguna con las partes de dicho contrato, en lo que afecta al mismo o a su resultado, son los llamados en el Derecho Romano "poenitus adquirence», los cuales respecto de aquel contrato o sus resultados, sólo tiene un deber general de respeto o abstención.

Tercer adquirente es el que ha entrado en relación jurídica con alguna de las partes de un contrato, respecto a lo que es materia $\mathbf{u}$ objeto del mismo, ya en virtud de un nuevo negocio juridico (comprador, donatario), ya por derivación de la Ley (acreedor singularmente privilegiado).

Una vez determinado quién es tercero en general o en Derecho Civil puro, fácil es precisar quién es tercero a los efectos del Registro de la Propiedad. Es el mismo que se acaba de examinar si 
bien en relación con el Registro. El Derecho Hipotecario se limita a regular la posición del mismo desde el punto de vista registral.

Si el tercero en el orden civil puro, no puede desconocer o rechazar un contrato otorgado por otros, si se cumplen ciertos requisitos de forma pública y certeza de fecha, transportando esta idea al terreno hipotecario, y substituyendo aquellos requisitos de forma pública, fecha cierta, por el de inscripción, resultará que a los efectos de Registro, los actos, negocios jurídicos o títulos no inscritos, no podrán afectar al tercero, o sea, que ante éste es inexistente todo cuanto no conste en los libros hipotecarios.

Ampliando esta idea a todo título o acción, podria decirse registralmente hablando, que ante tercero sólo existe en pro o en contra, lo que figura en el Registro, o sea, que sólo debe atenerse al contenido registral, refutado frente a él como única verdad existente.

$\mathrm{Y}$ aquí, en el orden hipotecario, es donde cobra especial relieve el tercero adquirente, no interesado en rigor el otro concepto de tercero simple. Con vistas a aquél, ha sido principalmente creado el Registro de la Propiedad, ya que cuando reuna los requisitos necesarios para la protección legal, dicho tercero es el beneficiado por la fe pública registral, resorte primordial de los regímenes hipotecarios. Cuando se habla de tercero hipotecario, se alude al tercero adquirente frente a una situación inscrita; por eso se le llama o denomina tercero hipotecario.

De todo lo expuesto resulta, que la noción de tercero hipotecario en nuestra Ley, puede definirse diciendo que, (es el adquirente considerado fuera de su condición de parte, frente a un determinado contenido registralm.

Julio de 1946.

José M.* Arroyo Barberia

Secietario del Ayuntamiento de Fuencarral (Madrid). 